\title{
Some values of tolerance in the Islamic educational thought and how to strengthen them within the Egyptian universities to confront community violence
}

\author{
Nancy Ahmed fouad and Amal Mohamed Ibrahem \\ Faculty of Education, South Valley University
}

\begin{abstract}
Some registry values in educational thought Islamic and how to strengthen it. within the Egyptian universities to address community violence. The study aims to reveal the concept of tolerance and the obstacles standing in the way of the spread of this concept in the Egyptian society, the unfinished study also advertises the most important values of tolerance in the Islamic Educational thought and published in the community. It also study imagine a proposal to promote the values of tolerance within universities airline to face repressive violence. on the descriptive approach adopted analytical study to analyze some of the verses of the Qur'an and the hadith Sharif and some of the sayings of educational THINKERS on the values of tolerance to develop meaningful indications.

and recommended study of the need to foster a climate of tolerance and value within the links by the administration, faculty members through school curricula, presidential statements and avoid the politicization of the scholastic universities and avoiding conflicts transmits to avoid student's community violence and chaos the intellectual collapse of moral values.
\end{abstract}

Keywords: the value of the registry; Egyptian universities; community violence

Citation Fouad and Ibrahem.,Requirements of Electronic Management in the Management of Kindergarten Institutions. SVU-Journal of abstract 2019, Vol.1: pp16 (retrieved from the Journal of Educational Sciences; 2018, No.35; pp 162).

Copyright: Publisher South Valley University. This is an open-access article distributed under the terms of the creative commons attribution license, which permits unrestricted use, distribution and reproduction in any medium provided the original author and source are created. 